\title{
Health-related quality of life: a retrospective study on local vs. microvascular reconstruction in patients with oral cancer
}

\author{
J. K. Meier ${ }^{1 *}$ (D) J. G. Schuderer ${ }^{1 \dagger}$, F. Zeman², Ch. Klingelhöffer ${ }^{1}$, M. Hullmann' ${ }^{1}$, G. Spanier ${ }^{1}$, T. E. Reichert ${ }^{1}$ and
} T. Ettl ${ }^{1}$

\begin{abstract}
Background: New medicinal and surgical oncological treatment strategies not only improve overall survival rates but continually increase the importance of Health-Related Quality of Life (HRQOL). The purpose of this retrospective cross-sectional study was to analyze $\mathrm{HRQOL}$ of patients with oral squamous cell carcinoma after ablative surgery and to evaluate predictive factors for HRQOL outcome.

Methods: The study included 88 patients with histologically confirmed oral squamous cell carcinoma of whom 42 had undergone local reconstruction (LR) and 46 microvascular reconstruction (MVR). During follow-up, all patients completed the University of Washington Quality of Life Questionnaire (UW-QOL) containing 12 targeted questions about the head and neck. Descriptive analyses were made for the tumor site, the T-stage, and adjuvant therapies. HRQOL was compared between the LR and the MVR group with parametric tests. Further analyses were impact of the tumor site, the T-status, and the time from surgery to survey on HRQOL. Statistics also included multivariate correlations and different interaction effects.

Results: HRQOL in the LR group was 'very good' with $84.3 \pm 13.7$ and 'good' in the MVR group with $73.3 \pm 16.5$ points. The physical domains swallowing $(p=0.00)$, chewing $(p=0.00)$, speech $(p=0.01)$, taste $(p=0.01)$, and pain $(p=0.04)$ were significantly worse in the MVR group. An increase in the T-status had a significant negative effect on swallowing $(p=0.01)$, chewing $(p=0.01)$, speech $(p=0.03)$, recreation $(p=0.05)$, and shoulder $(p=0.01)$ in both groups. Regarding the tumor site and subsequent loss of HRQOL, patients with squamous cell carcinoma on the floor of the mouth had significantly worse results in the categories pain $(p=0.002)$, speech $(p=0.002)$, swallowing $(p=0.03)$, activity $(p=0.02)$, and recreation $(p=0.01)$ than patients with tumors in the buccal mucosa. Speech $(p=0.03)$ and pain $(p=0.01)$ had improved 1 year after surgery.

Conclusion: Patients with flap reconstruction because of oral squamous cell carcinoma showed very good overall HRQOL. Outcomes for microvascular reconstruction were good, even in the case of larger defects. The T-status is a predictor for HRQOL. Swallowing, chewing, speaking, taste, and pain were the most important issues in our cohort. Implementing HRQOL questionnaires for the assessment of quality of life could further increase the treatment quality of patients with oral cancer.
\end{abstract}

Keywords: Oral carcinoma, Microvascular reconstruction, Health-related quality of life, University of Washington Quality of life questionnaire

\footnotetext{
* Correspondence: johannes.meier@ukr.de

†J. K. Meier and J. G. Schuderer contributed equally to this work and should

be regarded as joint First Authors.

${ }^{1}$ Department of Oral and Maxillofacial Surgery, University Medical Center

Regensburg, 93042 Regensburg, Germany

Full list of author information is available at the end of the article
}

(c) The Author(s). 2019 Open Access This article is distributed under the terms of the Creative Commons Attribution 4.0 International License (http://creativecommons.org/licenses/by/4.0/), which permits unrestricted use, distribution, and reproduction in any medium, provided you give appropriate credit to the original author(s) and the source, provide a link to the Creative Commons license, and indicate if changes were made. The Creative Commons Public Domain Dedication waiver (http://creativecommons.org/publicdomain/zero/1.0/) applies to the data made available in this article, unless otherwise stated. 


\section{Background}

Disease-free overall survival seems to have been the most important measure of success of oncological treatment for decades. Over the past few years, however, functional and psychosocial rehabilitation has progressively become an essential secondary outcome [1-5]. In this regard, the model of Health-Related Quality of Life (HRQOL) was developed to assess patient function and well-being after oncological therapy and to gain structured insight into disease- and therapy-derived problems $[2,6,7]$ HRQOL needs certainly to be seen as a complex multidimensional construct with a very individual character $[1,7,8]$. Different aspects and measurement instruments have been suggested to obtain comprehensive and comparable data on cancer patients [4-6]. For patients with head and neck cancer, targeted questionnaires on disease and site specificity have been developed [8]. Cancer originating from complex anatomical regions such as the oral cavity or the pharynx frequently requires extensive treatment with adverse effects on pivotal functions. Loss of swallowing, chewing, and speaking or having to deal with disfigured facial traits has an enormous physical and social impact on patients' lives [8-11]. To avoid impairment and to restore functionality, microvascular and local flap reconstruction techniques have been developed that are implemented according to the surgeon's expertise and the tumor characteristics [12-14]. In larger T-graded tumors, microvascular reconstruction, for instance with radial or fibula flaps, provides reliable functional and esthetic outcomes [9, 15]. Nevertheless, the therapeutic regimen is being constantly further developed, and data on oral cancer are still somewhat limited [8]. Further aspects of HRQOL have to be identified in the future to be able to use quality of life as a standardized outcome parameter after flap reconstruction and to enhance oncological outcome while minimizing postoperative handicaps $[8,10,13]$.

The aim of this study was to measure HRQOL in patients with oral squamous cell carcinoma after oncological and reconstructive surgery. Predictors for HRQOL were identified by means of the targeted University of Washington Quality of Life Questionnaire (UW-QOL) followed by the evaluation of retrospective data.

\section{Methods}

\section{Study design}

The retrospective cross-sectional study was conducted at the Clinic of Oral and Maxillofacial Surgery of the University Medical Center Regensburg over a period of 18 months under the approval of the local Ethics Committee and according to the regulations of the protection of data privacy. Included patients were staged for squamous cell carcinoma of the oral cavity according to the current UICC TNM classification [16]. The nodal status was documented but not incorporated into this study.
All patients had undergone oncological tumor resection with curative intent and immediate reconstruction after the staging process according to the current German guidelines for the treatment of cancer in the oral cavity [17]. Therefore, the common reconstructive techniques carried out were primary wound closure, different local flaps, and free tissue transfer. Microvascular reconstruction comprised radial forearm flaps, fibula flaps, anterior- lateral thigh flaps, lateral upper arm flaps, and iliac crest. Neck dissection and adjuvant therapies such as radiotherapy were initiated based on the decision of the local tumor board. ICD coding of the tumor sites was based on the documented anatomical subsites of the primary tumor localization.

All patients had completed the validated German Version of the University Of Washington Quality Of Life Questionnaire (UW-QOL) including 12 targeted head and neck categories at least 3 months after surgery [18-20]. Following Lowe et al., UW-QOL results were transformed into scores from 0 to 100 ; 0 to 20 was rated as 'very bad' HRQOL, 20 to 40 as 'bad', 40 to 60 as 'moderate', 60 to 80 as 'good', and 80 to 100 as 'very good' [20].

Inclusion criteria for the study were:

- Histologically confirmed oral squamous cell carcinoma,

- Oncological surgery with immediate local or microvascular reconstruction at our clinic over aperiod of 18 months, and

- Being disease-free at the time of the survey.

Exclusion criteria for the study were:

- Any other histological type of oral or extraoral carcinoma,

- Tumor site in the nasopharynx or hypopharynx,

- Unsuccessful local or free flap reconstruction,

- M1-status or planned palliative treatment, and

- Synchronous or metachronous second primary oral squamous cell carcinoma or tumor recurrence.

\section{Statistical analysis}

Descriptive analyses were made for the tumor site, the T-stage, and adjuvant therapies. HRQOL was presented analogue to the questionnaire categories and score systems [18]. The following factors were analyzed with regard to their impact on HRQOL: the type of reconstruction (MVR or LR), the size of the tumor (T-status), the tumor site (floor of the mouth or buccal mucosa) and the postoperative survey time (3-6 months, 1 year, $1-2$ years and $\geq 2$ years). Univariate analyses were conducted using the chi squared and the Fisher's exact tests and the Student's $t$ test. $P$-values $<0.05$ were considered statistically significant. 
ANOVAs were calculated to check multivariate correlations of reconstruction and other variables on HRQOL. To rule out interaction effects, the interaction term of reconstruction and other variables were included in the model. Subsequently, to rule out the possibility of another variable in the model changing the relationship between reconstruction and HRQOL, models were calculated for non-significant interaction terms, and main effects were investigated. Post hoc power analyses was conducted using G*Power 3.1.9.4.

All statistical analyses were conducted using IBM SPSS Statistics Version 21.0.

\section{Results}

\section{Clinical characteristics of the patients}

Overall, 88 patients had undergone oncological surgery with local or free microvascular reconstruction at our clinic over a period of 18 months. Regarding the T-classification, $52.2 \%$ of our patients had T1-status, 28.8\% T2-status, and 18.1\% T4-status. Only 1 patient had been treated for a T3-tumor. 80 patients $(90.9 \%)$ underwent neck dissection, and 17 patients (19.3\%) received adjuvant therapy. $46 \%$ of the patients had completed the survey within 1 year after surgery, 54\% after 1 year and more. LR was mainly used for smaller T1-defects (69\%), while MVR was almost equally used for T2-T4-defects. The clinical characteristics of our patients are summarized in Table 1 . LR was possible in 42 patients, whereas 46 patients were received a microvascular transplant (MVR). Tumors on the tongue were mostly treated with local flap therapy (45.2\%); in contrast, tumors on the floor of the mouth were primarily reconstructed with a microvascular transplant (56.5\%). Primary tumor sites and the type of reconstruction are shown and encoded in Table 2.

\section{UW-QOL scores}

The UW-QOL data shown in Table 3 refer to physical issues from appearance to taste and to social issues from pain to anxiety [20]. The comparison of the mean scores of the LR and MVR groups showed that the domains swallowing $(p=0.001)$, chewing $(p=0.000)$, speech $(p=$ $0.011)$, taste $(p=0.014)$, and pain $(p=0.036)$ were significantly worse in the MVR group. The LR group showed 'very good' HRQOL with $84.3 \pm 13.7$, the MVR group only 'good' HRQOL with $73.3 \pm 16.5$ points $(p=0.001)$.

Table 1 Clinical characteristics of the study participants

\begin{tabular}{|c|c|c|c|}
\hline \multirow[b]{2}{*}{$N=88$} & \multicolumn{2}{|c|}{ Types of reconstruction } & \multirow[b]{2}{*}{ Total $n=88$} \\
\hline & $\operatorname{LR} n=42(47.8 \%)$ & MVR $n=46(52.2 \%)$ & \\
\hline \multicolumn{4}{|l|}{ Sex } \\
\hline Men & $27(64.2 \%)$ & $31(67.4 \%)$ & $58(65.9 \%)$ \\
\hline Women & $15(35.7 \%)$ & $15(32.6 \%)$ & $30(34.1 \%)$ \\
\hline Age & $60.4 \pm 12.0 y$ & $58.9 \pm 9.7$ y & $59.7 \pm 10.8 y$ \\
\hline \multicolumn{4}{|l|}{ T-status } \\
\hline $\mathrm{T} 1$ & $29(69.0 \%)$ & $17(33.0 \%)$ & $46(52.2 \%)$ \\
\hline $\mathrm{T} 2$ & $9(21.4 \%)$ & $16(34.8 \%)$ & $25(28.4 \%)$ \\
\hline T3 & $1(2.3 \%)$ & 0 & $1(1.1 \%)$ \\
\hline T4 & $3(7.1 \%)$ & $13(28.3 \%)$ & $16(18.1 \%)$ \\
\hline \multicolumn{4}{|l|}{ Adjuvant therapy } \\
\hline Radiotherapy & $4(9.5 \%)$ & $5(10.8 \%)$ & $9(10.2 \%)$ \\
\hline Radio chemotherapy & $1(2.3 \%)$ & $5(10.8 \%)$ & $6(6.8 \%)$ \\
\hline Chemotherapy alone & $1(2.3 \%)$ & $1(2.2 \%)$ & $2(2.3 \%)$ \\
\hline No adjuvant therapy & $36(85.7 \%)$ & $35(76.1 \%)$ & $71(80.6 \%)$ \\
\hline \multicolumn{4}{|c|}{ Time from surgery to survey } \\
\hline $3-6$ months & $12(28.5 \%)$ & $15(32.6 \%)$ & $26(29.5 \%)$ \\
\hline 1 year & $9(21.4 \%)$ & $5(10.8 \%)$ & $14(15.9 \%)$ \\
\hline $1-2$ years & $5(11.9 \%)$ & $6(13 \%)$ & $11(12.5 \%)$ \\
\hline$\geq 2$ years & $17(40.4 \%)$ & $20(43.5 \%)$ & 37 (42\%) \\
\hline \multicolumn{4}{|l|}{ Neck dissection } \\
\hline Yes & 37 (88.1\%) & 43 (93.5\%) & 80 (90.9\%) \\
\hline No & 5 (11.9\%) & $3(6.5 \%)$ & 8 (9.1\%) \\
\hline
\end{tabular}

$L R$ local reconstruction, MVR microvascular reconstruction 
Table 2 Primary tumor sites and applied reconstructive techniques

\begin{tabular}{|c|c|c|c|c|c|c|c|}
\hline \multirow[b]{2}{*}{$n=88$} & \multicolumn{7}{|c|}{ Primary tumor site } \\
\hline & $\begin{array}{l}\text { Floor of mouth } \\
n=34\end{array}$ & $\begin{array}{l}\text { Tongue } \\
n=27\end{array}$ & $\begin{array}{l}\text { Buccal mucosa } \\
n=13\end{array}$ & $\begin{array}{l}\text { Alveolar mucosa } \\
n=10\end{array}$ & $\begin{array}{l}\text { Base of the tongue } \\
n=3\end{array}$ & $\begin{array}{l}\text { Retromolar region } \\
n=1\end{array}$ & Total \\
\hline ICD-Codes & C04.8 & C02.0 & C06.0 & C03.9 & C01 & C06.2 & \\
\hline$L R n=42$ & $n=8$ & $n=19$ & $n=7$ & $n=6$ & $n=2$ & $n=0$ & \\
\hline Primary wound closure & 5 & 11 & 4 & 2 & 2 & - & 24 \\
\hline Local flap & 1 & 8 & 2 & 4 & - & - & 15 \\
\hline Free skin & 2 & - & 1 & - & - & - & 3 \\
\hline$M V R n=46$ & $n=26$ & $n=8$ & $n=6$ & $n=4$ & $n=1$ & $n=1$ & \\
\hline Forearm flap & 17 & 8 & 6 & 2 & 1 & 1 & 35 \\
\hline Fibula flap & 5 & - & - & 2 & - & - & 7 \\
\hline Antero lateral thigh flap & 1 & - & - & - & - & - & 1 \\
\hline Lateral upper arm flap & 1 & - & - & - & - & - & 1 \\
\hline \|liac crest & 2 & - & - & - & - & - & 2 \\
\hline
\end{tabular}

$L R$ local reconstruction, $M V R$ microvascular reconstruction

Investigating the effects that tumor size might have on HRQOL, we found that increases in the T-stage significantly impaired swallowing $(p=0.01)$, chewing $(p=0.01)$, speech $(p=0.03)$, recreation $(p=0.05)$, and shoulder $(p$ $=0.01$ ) (Table 4 and Fig. 1). Investigations into the influence of the tumor site and subsequent loss of HRQOL showed that patients with squamous cell carcinoma on the floor of the mouth had significantly worse results in the categories pain $(p=0.002)$, speech $(p=0.002)$, swallowing $(p=0.03)$, activity $(p=0.02)$, and recreation $(p=$ 0.01 ) than patients with tumors in the buccal mucosa. Regarding the time from surgery to survey, $42 \%$ of the patients completed the survey more than 2 years after surgery. Almost $30 \%$ of patients completed the survey 3 to 6 months after surgery. Pain was rated as significantly less 1 year $(p=0.01)$ and $\geq 2$ years $(p=0.03)$ after surgery than after 3 to 6 months after surgery. Furthermore, the category speech $(p=0.01)$ was significantly improved 1 to 2 years and $\geq 2$ years $(p=0.03)$ after surgery compared to the ratings after 1 year. Overall, the ratings of the HRQOL domains were not significantly improved less or equal 1 year from surgery to survey compared to ratings greater or equal 1 year from surgery to survey.

Multivariate analyses of reconstruction, third variables, and HRQOL showed that interaction effects were not statistically significant $(p>0.05)$.

If third variables were added into the model, relationships between reconstruction and HRQOL only changed with regard to chemotherapy $(p=0.004)$. The T-status was a predictor for HRQOL scores but lost significance under multivariate observation $(p=0.051)$. All multivariate and interaction effects are presented in Table 5.

Post hoc power analyses showed a power of 0.98 on HRQOL tests. The effect size of T-status on HRQOL was moderate $(\mathrm{d}=0.7)$.

\section{Discussion}

Ablative surgery for oral cancer, for instance resection of parts of the tongue, the floor of mouth, or the jaw bones, has a major influence on the quality of life of patients. Reconstruction of the surgical defect is mandatory to restore function and appearance [10, 21]. Small defects can be reconstructed with local techniques such as primary closure, local flaps such as tongue flaps or nasolabial flaps, or in some patients with free skin transplants. Larger defects often require more elaborate techniques. For many years, pedicled flaps such as pectoralis major flaps were preferred. Over the past 20 years, reconstruction with free micro vascularized transplants has become standard, improving oncological and functional outcomes $[11,14]$. Quality of Life has become a constant marker of success in any oncological treatment. Microvascular and local flap techniques have been widely used to restore functionality in patients with head and neck cancer. In this study, we investigated what parameters influence HRQOL and how quality of life differs between patients with complex and local reconstructions. We used the University of Washington Quality of Life questionnaire because it is well established, short, and easy to understand.

In our study, HRQOL was significantly influenced by the type of reconstruction. Patients treated with a microvascular flap scored significantly worse in various oral domains with an overall difference of 10 points. There seems to be a variety of reasons for the better health-related outcome of local reconstructive techniques in comparison to microvascular free flap reconstructions in our cohort. First of all, microvascular reconstruction may result in higher donor side morbidity and requires more complex postoperative management. In this study, radial forearm flaps and fibula flaps 
Table 3 Domains and mean scores of the University of Washington Quality of Life Questionnaire assessed globally and separately for the LR and MVR groups

\begin{tabular}{|c|c|c|c|c|c|}
\hline UWQLQ & & $\mathrm{N}$ & Score mean & SD & $P$-value \\
\hline & GLOBAL & 87 & 79.0 & 21.2 & \\
\hline \multirow[t]{3}{*}{ Appearance } & $L R$ & 41 & 82.3 & 20.3 & 0.172 \\
\hline & MVR & 46 & 76.1 & 21.7 & \\
\hline & GLOBAL & 87 & 78.9 & 26.0 & \\
\hline \multirow[t]{3}{*}{ Swallowing } & $L R$ & 42 & 88.6 & 22.9 & 0.001 \\
\hline & MVR & 45 & 70 & 25.8 & \\
\hline & GLOBAL & 86 & 78.4 & 26.0 & \\
\hline \multirow[t]{3}{*}{ Chewing } & $L R$ & 42 & 89.3 & 20.8 & 0.000 \\
\hline & MVR & 44 & 68.2 & 26.6 & \\
\hline & GLOBAL & 86 & 78.8 & 18.8 & \\
\hline \multirow[t]{3}{*}{ Speech } & $L R$ & 42 & 84.0 & 17.3 & 0.011 \\
\hline & MVR & 44 & 73.9 & 19.1 & \\
\hline & GLOBAL & 86 & 77.3 & 25.7 & \\
\hline \multirow[t]{3}{*}{ Saliva } & $L R$ & 42 & 80.7 & 24.9 & 0.235 \\
\hline & MVR & 44 & 74.1 & 26.4 & \\
\hline & GLOBAL & 87 & 76.0 & 27.6 & \\
\hline \multirow[t]{3}{*}{ Taste } & $L R$ & 42 & 83.6 & 20.8 & 0.014 \\
\hline & MVR & 45 & 69.1 & 31.5 & \\
\hline & GLOBAL & 87 & 81.3 & 24.8 & \\
\hline \multirow[t]{3}{*}{ Pain } & $L R$ & 41 & 87.2 & 21.0 & 0.036 \\
\hline & MVR & 46 & 76.1 & 26.9 & \\
\hline & GLOBAL & 88 & 76.1 & 23.0 & \\
\hline \multirow[t]{3}{*}{ Activity } & $L R$ & 42 & 80.9 & 21.9 & 0.060 \\
\hline & MVR & 46 & 71.7 & 23.3 & \\
\hline & GLOBAL & 87 & 77.8 & 26.2 & \\
\hline \multirow[t]{3}{*}{ Recreation } & $L R$ & 42 & 82.7 & 26.8 & 0.095 \\
\hline & MVR & 45 & 73.3 & 25.2 & \\
\hline & GLOBAL & 80 & 78.7 & 30.8 & \\
\hline \multirow[t]{3}{*}{ Shoulder } & $L R$ & 38 & 84.5 & 24.7 & 0.115 \\
\hline & MVR & 42 & 73.6 & 34.9 & \\
\hline & GLOBAL & 87 & 78.4 & 22.6 & \\
\hline \multirow[t]{3}{*}{ Mood } & $L R$ & 42 & 83.3 & 20.4 & 0.051 \\
\hline & MVR & 45 & 73.9 & 23.8 & \\
\hline & GLOBAL & 87 & 81.9 & 18.6 & \\
\hline \multirow[t]{2}{*}{ Anxiety } & $L R$ & 42 & 84.3 & 15.2 & 0.263 \\
\hline & MVR & 45 & 79.8 & 21.4 & \\
\hline
\end{tabular}

$L R$ local reconstruction, MVR microvascular reconstruction $P$-values $=$ comparison of mean values LR/MVR for two independent samples using the t-test

were the mostly used types of microvascular flaps. De Witt et al. could show in their study on donor side morbidity in radial forearm flaps that basically one out of three patients had substantial functional limb complaints 6 months after surgery [22]. Literature reports have
Table 4 Effect of the increase in the T-stage on HRQOL domains

\begin{tabular}{ll}
\hline Appearance & $p=0.24$ \\
\hline Swallowing & $p=0.01$ \\
Chewing & $p=0.01$ \\
Speech & $p=0.03$ \\
Saliva & $p=0.3$ \\
Taste & $p=0.12$ \\
Pain & $p=0.94$ \\
Activity & $p=0.24$ \\
Recreation & $p=0.05$ \\
Shoulder & $p=0.01$ \\
Mood & $p=0.3$ \\
Anxiety & $p=0.3$ \\
\hline
\end{tabular}

described donor and recipient site complications in up to $45 \%$ of patients [23]. Furthermore, free fibula harvest is associated with multiple postoperative complications such as ischemia of the ipsilateral foot, wound dehiscence, and chronic pain [24-26] with a possible negative impact on global QOL scores. With regard to delicate intraoral function, the patients with microvascular reconstruction in our study had significantly impaired HRQOL in chewing $(p=0.00)$, swallowing $(p=0.001)$, speech $(p=0.011)$, and taste $(p=0.014)$. The consecutive destruction of nerve, bone, and muscle structures negatively influences chewing and speaking; additionally, intraoral flaps can often be relatively voluminous and inflexible, thus interfering with usual mastication and deglutition [27]. The T-status was also a predictor for HRQOL scores. Whereas $62 \%$ of MVRs were conducted in the case of T2-T4-sized tumors, $69 \%$ of local reconstructions were carried out in the case of T1 tumors. This trend may be due to the advanced T-status that naturally requires more extensive surgery to achieve R0 resection [28]. Nevertheless, we found that the predictive character of the T-status was decreasing under multivariate observation. Additionally, reconstructions of the floor of the mouth showed worse scores than those for buccal mucosa (Table 6). Particularly the floor of the mouth guarantees mobility of the tongue; thus, defects in this region significantly impair swallowing, mastication, and speaking. In contrast, reconstructed defects in the buccal mucosa are more associated with salivary retention and pain [21, 29]. The tongue is also essential for propulsion processes. Dwivedi et al. found low scores for swallowing in patients with cancer of the tongue [28, 30]. Furthermore, microvascular transplant techniques are time-consuming and require extended operating times, which could also affect outcomes, particularly in elderly patients $[31,32]$. In addition, adjuvant therapies such as chemotherapy and neck dissection are more 


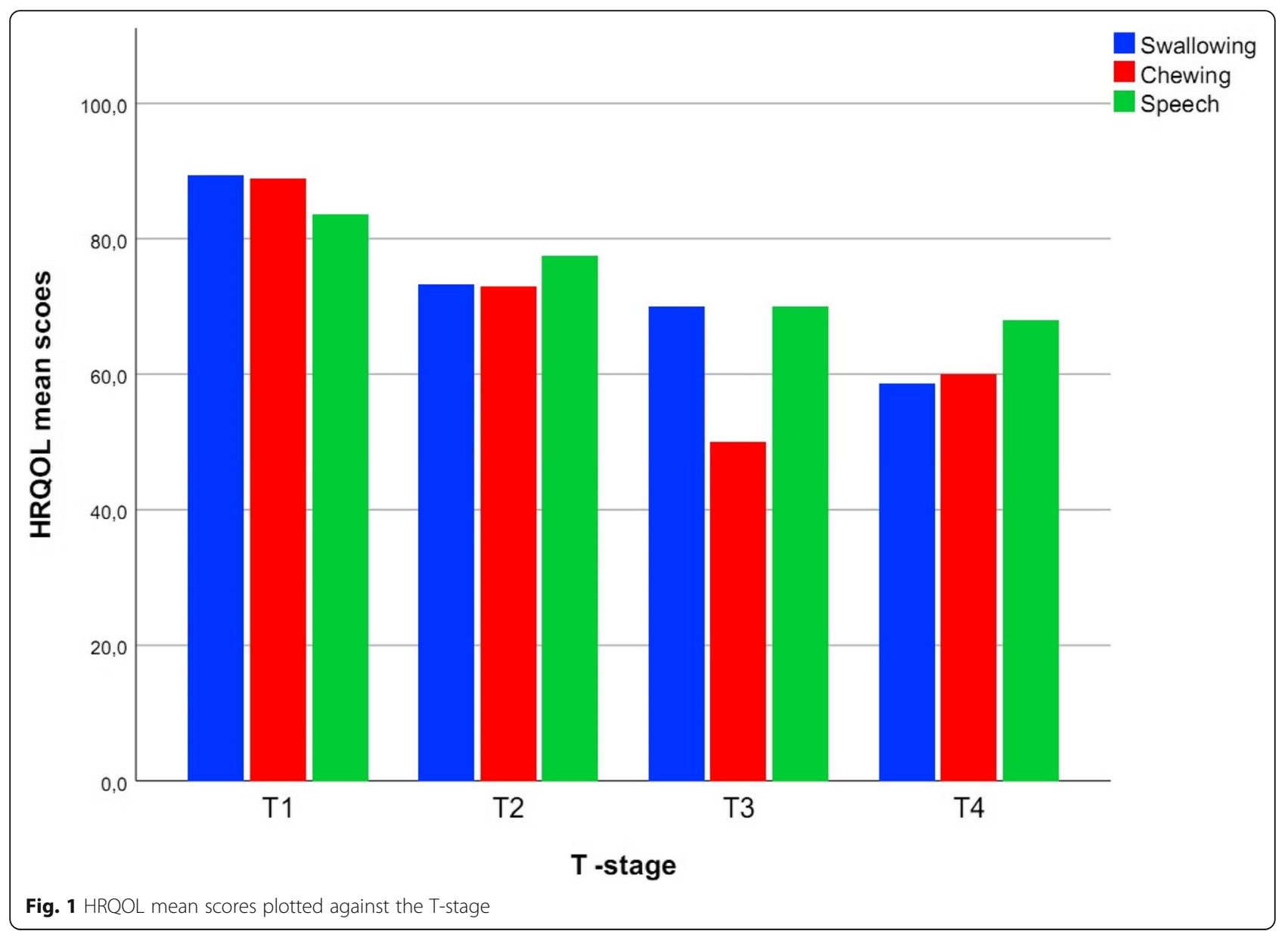

frequently used in the case of increasing UICC staging. In our study, the number of adjuvant therapies was higher in the MVR group, and chemotherapy had an impact on HRQOL. Among others, chemotherapy and radiotherapy lead to xerostomia and mucositis which could explain the increasingly impairment in swallowing, chewing, speech, and taste as well as the increased level of pain [33, 34]. In contrast, in adequate defects, local reconstructive approaches allow the use of local tissue anatomy, which is not only usually followed by uncomplicated healing but also avoids nutritional graft problems because no vessel anastomosis is required. The procedures are quick to carry out and may even be achieved under local anesthesia in selected patients, facilitating favorable outcomes [35].

Two key elements of studies observing HRQOL are evaluating postoperative time and the point of interrogation [36]. Assuming that oncological treatment itself is an extraordinary experience for patients in generally reduced health, we started HRQOL evaluation at least 3 months after surgery. Since data were only collected postoperatively, we had no baseline of physical and social functioning. Previous studies have shown that
HRQOL experiences sometimes change over the first 12 months after surgery. However, such aggravations seem to stabilize within 1 year after surgery and can be used as a long-term indicator $[5,7,10]$. Comparing domains with regard to the point in time the survey was carried out, we found differences in the category pain that had improved within the first year and two years after surgery. The category speech had also improved 1 year after surgery. No interaction effects were found between postoperative time and HRQOL under reconstructive therapy. The literature lacks information on postoperative oral functioning. Naturally, postoperative healing processes and functional restitution take their time, so that the already mentioned period of 1 year seems to be realistic for the healing process.

Finally, our patients with microvascular reconstruction nevertheless showed global scores of 73.3, which is still considered good quality of life. Markkanen-Leppänen et al. found scores comparable to our findings [37]. In consideration of these findings, there are reasons to opt for a microvascular graft in the oral cavity. MVR allows greater flexibility in both planning and implementation. Septocutaneous ALT flaps are used because of their 
Table 5 Multivariate analyses for interaction effects (ANOVAs) and main effect on $\mathrm{HRQOL}$

\begin{tabular}{|c|c|c|c|}
\hline & Model & Variable & $P$-value \\
\hline \multirow[t]{8}{*}{ Interaction effects } & 1 & reconstruction*age & 0.351 \\
\hline & 2 & reconstruction*sex & 0.173 \\
\hline & 3 & reconstruction*chemotherapy & 0.672 \\
\hline & 4 & reconstruction*tumor site & 0.079 \\
\hline & 6 & reconstruction*T-status & 0.746 \\
\hline & 7 & reconstruction*neck dissection & 0.771 \\
\hline & 8 & reconstruction*radiation & 0.984 \\
\hline & 9 & reconstruction*postoperative time & 0.163 \\
\hline \multirow[t]{16}{*}{ Main effects } & 10 & reconstruction & 0.001 \\
\hline & & age & 0.916 \\
\hline & 11 & reconstruction & 0.001 \\
\hline & & sex & 0.187 \\
\hline & 12 & reconstruction & 0.003 \\
\hline & & chemotherapy & 0.004 \\
\hline & 13 & reconstruction & 0.009 \\
\hline & & tumor site & 0.462 \\
\hline & 15 & reconstruction & 0.012 \\
\hline & & T-status & 0.051 \\
\hline & 16 & reconstruction & 0.002 \\
\hline & & neck dissection & 0.156 \\
\hline & 17 & reconstruction & 0.003 \\
\hline & & radiation & 0.854 \\
\hline & 18 & reconstruction & 0.002 \\
\hline & & postoperative time & 0.622 \\
\hline
\end{tabular}

Level of significance $p<0.05$

Postoperative time $=$ time from surgery to survey

Table 6 Difference in HRQOL between carcinoma on floor of the mouth and carcinoma in the buccal mucosa

\begin{tabular}{ll}
\hline Appearance & $p=0.6$ \\
\hline Swallowing & $p=0.03$ \\
Chewing & $p=0.09$ \\
Speech & $p=0.00$ \\
Saliva & $p=0.6$ \\
Taste & $p=0.8$ \\
Pain & $p=0.00$ \\
Activity & $p=0.02$ \\
Recreation & $p=0.01$ \\
Shoulder & $p=0.2$ \\
Mood & $p=0.3$ \\
Anxiety & $p=0.9$ \\
\hline
\end{tabular}

Level of significance $p<0.05$ enormous flexibility and comparably low donor site morbidity, especially in comparison to pedicled pectoralis major flaps that are associated with greater aesthetic donor site issues, particularly in female patients with breast deformation [38-41]. Furthermore, ALT flaps enable wider tumor resections with R0 margins as well as sufficient defect closures $[9,10]$. To improve outcome for oncological patients, it seems necessary to implement HRQOL assessment in preoperative planning and patient management.

This study has several limitations. First of all, because of the unavailability of pre-treatment data, UW-QOL scores could not be compared with preoperative functioning scores to evaluate if our results reflect long-term HRQOL. Since we only used one targeted head and neck questionnaire but oncological patients are treated interdisciplinary, our results could have been influenced by other medical conditions. Furthermore, HRQOL should be assessed in a larger cohort to reach better uniform distribution. In the future, it seems reasonable to include general cancer questionnaires in the assessment setup. This in mind, we accept that our results only allow limited conclusions.

\section{Conclusion}

Patients' reconstruction with microvascular flaps after oral squamous cell carcinoma has good postoperative HRQOL. The T-status is a predictor for HRQOL. Swallowing, chewing, speaking, taste, and pain were the most important issues in our cohort.

\section{Abbreviations}

HRQOL: Health-Related Quality of Life; LR: Local reconstruction;

MVR: Microvascular reconstruction; UWQLQ: University of Washington Quality of Life Questionnaire

\section{Acknowledgements}

Not applicable.

Funding

There was no funding.

Availability of data and materials

The datasets used and/or analyzed during the current study are available from the corresponding author on reasonable request.

Authors' contributions

JKM, JGS, FZ, CK, MH, GS, TR and TE contributed to this work, read and approved the final manuscript.

Ethics approval and consent to participate

All procedures conducted in this study were in accordance with the ethical standards of the institutional and research committee and with the 1964 Helsinki declaration and its later amendments or comparable ethical standards. This study has the committee reference number 14-101-0095 and was approved by the local Ethics Committee of the University Medical Center Regensburg. All study participants gave their written informed consent.

\section{Consent for publication}

Informed consent was written obtained from all individual participants included in the study. 


\section{Competing interests}

The authors declare that they have no competing interests.

\section{Publisher's Note}

Springer Nature remains neutral with regard to jurisdictional claims in published maps and institutional affiliations.

\section{Author details}

'Department of Oral and Maxillofacial Surgery, University Medical Center Regensburg, 93042 Regensburg, Germany. ${ }^{2}$ Center for Clinical Studies, University Medical Center Regensburg, Regensburg, Germany.

\section{Received: 4 December 2018 Accepted: 9 April 2019}

\section{Published online: 27 April 2019}

\section{References}

1. Bakas T, Mclennon SM, Carpenter JS, et al. Systematic review of healthrelated quality of life models. Health Qual Life Outcomes. 2012;10(1):134.

2. Chandu A, Smith AC, Rogers SN. Health-related quality of life in Oral Cancer: a review. J Oral Maxillofac Surg. 2006;64(3):495-502.

3. Renneberg B, Lippke S. Lebensqualität. In: Renneberg B, Hammelstein P, editors. (Hrsg.) Gesundheitspsychologie. Heidelberg: Springer Medizin verlag; 2012. p. 29-33.

4. Rogers SN, Hannah L, Lowe D, Magennis PJ. Quality of life 5-10 years after primary surgery for oral and oro-pharyngeal cancer. J Craniomaxillofac Surg. 1999:27(3):187-91.

5. Borggreven PA, Aaronson NK, IMV-D L, et al. Quality of life after surgical treatment for oral and oropharyngeal cancer: a prospective longitudinal assessment of patients reconstructed by a microvascular flap. Oral Oncol. 2007:43(10):1034-42

6. Cella DF, Tulsky DS. Measuring quality of life today: methodologic aspects. Oncology. 1990;4(5):29-38.

7. Rogers SN, Lowe D, Brown JS, Vaughan ED. The University of Washington head and neck cancer measure as a predictor of outcome following primary surgery for oral cancer. Head Neck. 1999:21(5):394-401.

8. Murphy BA, Ridner S, Wells $N$, et al. Quality of life research in head and neck cancer: a review of the current state of the science. Crit Rev Oncol Hematol. 2007;62(3):251-67.

9. Canis M, Weiss BG, Ihler F, Hummers-Pradier E, Matthias C, Wolff HA. Quality of life in patients after resection of pT3 lateral tongue carcinoma: microvascular reconstruction versus primary closure. Head Neck. 2015;38(1):89-94.

10. Schliephake $H$, Jamil M. Prospective evaluation of quality of life after oncologic surgery for oral cancer. Int J Oral Maxillofac Surg. 2002;31(4):427-33.

11. Hanasono MM, Friel MT, Klem C. Impact of reconstructive microsurgery in patients with advanced oral cavity cancers. Head Neck. 2009;31:1289-96.

12. Mcconnel FMS, Pauloski BR, Logemann JA, et al. Functional results of primary closure vs flaps in Oropharyngeal reconstruction. Arch Otolaryngol Head Neck Surg. 1998:124(6):625.

13. Peisker A, Raschke G, Guentsch A, Roshanghias K, Eichmann F, SchultzeMosgau S. Longterm quality of life after oncologic surgery and microvascular free flap reconstruction in patients with oral squamous cell carcinoma. Med Oral Patol Oral Cir Bucal. 2016:21(4):e420-4.

14. Urken ML, Moscoso JF, Lawson W, Biller HF. A systematic approach to functional reconstruction of the Oral cavity following partial and Total Glossectomy. Arch Otolaryngol Head Neck Surg. 1994;120(6):589-601.

15. Nakatsuka T, Harii K, Asato H, et al. Analytic review of 2372 free flap transfers for head and neck reconstruction following cancer resection. J Reconstr Microsurg. 2003;19:363-36.

16. Sobin LH, Compton CC. TNM seventh edition: Whats new, whats changed. Cancer. 2010;116(22):5336-9.

17. AWMF. Leitlinienprogramm Onkologie; Deutsche Krebsgesellschaft e.V., deutsche Krebshilfe e.V., S3 Leitlinie Mundhöhlenkarzinom. 2012.

18. Rogers S, Laher S, Overend L, Lowe D. Importance-rating using the University of Washington Quality of life questionnaire in patients treated by primary surgery for oral and oro-pharyngeal cancer. J Cranio-Maxillofac Surg. 2002;30(2):125-32.

19. Rogers SN, Gwanne S, Lowe D, Humphris G, Yueh B, Weymuller EA. The addition of mood and anxiety domains to the University of Washington quality of life scale. Head Neck. 2002;24(6):521-9.

20. Lowe D, Rogers SN: University of Washington Quality of life questionnaire (UW -QOL V4), guidance for scoring and presentation; (http://wwW. hancsupport.com/sites/default/files/assets/pages/uwqol-v4-german.pdf) accessed 19 Mar 2019

21. Chinn SB, Myers JN. Oral cavity carcinoma: current management, controversies, and future directions. J Clin Oncol. 2015:33(29):3269-79.

22. De Witt CA, de Bree R, Verdonck-de Leeuw IM, Quak JJ, Leemans CR. Donor site morbidity of the fasciocutaneous radial forearm flap: what does the patient really bother? Eur Arch Otorhinolaryngol. 2007;264(8):929-34.

23. Arganbright JM, Tsue TT, Girod DA, et al. Outcomes of the Osteocutaneous radial forearm free flap for mandibular reconstruction. JAMA Otolaryngol Head Neck Surg. 2013;139(2):168-72.

24. Kim D, Orron DE, Skillman JJ. Surgical significance of popliteal arterial variants. A unified angiographic classification. Ann Surg. 1989;210:776-81.

25. Momoh AO, Yu P, Skoracki RJ, Liu S, Feng L, Hanasono MM. A prospective cohort study of fibula free flap donor-site morbidity in 157 consecutive patients. Plast Reconstr Surg. 2011;128(3):714-20.

26. Ling XF, Peng $X$. What is the price to pay for a free fibula flap? A systematic review of donor-site morbidity following free fibula flap surgery. Plast Reconstr Surg. 2012;129:65774.

27. Zuydam A, Lowe D, Brown J, Vaughan E, Rogers S. Predictors of speech and swallowing function following primary surgery for oral and oropharyngeal cancer. Clin Otolaryngol. 2005;30:428-37.

28. Dwivedi RC, Chisholm EJ, Khan AS, et al. An exploratory study of the influence of clinico-demographic variables on swallowing and swallowingrelated quality of life in a cohort of oral and oropharyngeal cancer patients treated with primary surgery. Eur Arch Otorhinolaryngol. 2012;269:1233.

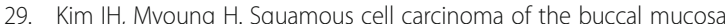
involving the masticator space: a case report. J Korean Assoc Oral Maxillofac Surg. 2017:43(3):191-6.

30. McConnel FM. Analysis of pressure generation and bolus transit during pharyngeal swallowing. Laryngoscope. 1988;98(1):71-8.

31. Pierre CS, Dassonville O, Chamorey E, Poissonnet G, Ettaiche M, Santini J, Peyrade F, Benezery K, Sudaka A, Bozec A. Long-term quality of life and its predictive factors after oncologic surgery and microvascular reconstruction in patients with oral or oropharyngeal cancer. Eur Arch Otorhinolaryngol. 2014;271(4):801-7.

32. Colangelo LA, Logemann JA, Pauloski BR, Pelzer JR, Rademaker AW. T stage and functional outcome in oral and oropharyngeal cancer patients. Head Neck. 1996;18(3):259-68.

33. Connor NP, Cohen SB, Kammer RE, Sullivan PA, Brewer KA, Hong TS, Chappell RJ, Harari PM. Impact of conventional radiotherapy on healthrelated quality of life and critical functions of the head and neck. Int J Radiat Oncol Biol Phys. 2006:65(4):1051-62.

34. Epstein JB, Robertson M, Emerton S, Phillips N, Stevenson-Moore P. Quality of life and oral function in patients treated with radiation therapy for head and neck cancer. Head Neck. 2001;23(5):389-98.

35. Squaquara R, Kim Evans KF, Spanio di Spilimbergo S, Mardini S. Intraora reconstruction using local and regional flaps. Semin Plast Surg. 2010; 24(2):198-211.

36. Djan $\mathrm{R}$, et al. A systematic review of questionnaires to measure the impact of appearance on quality of life for head and neck cancer patients. J Plast Reconstr Aesthet Surg. 2013;66(5):647-59.

37. Markkanen-Leppänen M, Mäkitie AA, Haapanen ML, Suominen E, AskoSeljavaara S. Quality of life after free-flap reconstruction in patients with oral and pharyngeal cancer. Head Neck. 2006:28(3):210-6.

38. Suh JD, Sercarz JA, Abemayor E, Calcaterra TC, Rawnsley JD, Alam D, Blackwell KE. Analysis of outcome and complications in 400 cases of microvascular head and neck reconstruction. Arch Otolaryngol Head Neck Surg. 2004;130(8):962-6.

39. Wong $\mathrm{CH}$, Wei FC. Anterolateral thigh flap. Head Neck. 2010;32:529-40.

40. Zhang X, Li MJ, Fang QG, Sun CF. A comparison between the pectoralis major myocutaneous flap and the free anterolateral thigh perforator flap for reconstruction in head and neck cancer patients: assessment of the quality of life. J Craniofac Surg. 2014;25(3):868-71.

41. Li W, Xu Z, Liu F, Huang S, Dai W, Sun C. Vascularized free forearm flap versus free anterolateral thigh perforator flaps for reconstruction in patients with head and neck cancer: assessment of quality of life. Head Neck. 2013; 35(12):1808-13. 